\title{
Hubungan diabetes melitus dengan kualitas tidur
}

\author{
${ }^{1}$ Inry N. Tentero \\ ${ }^{2}$ Damayanti H. C. Pangemanan \\ ${ }^{2}$ Hedison Polii
}

\author{
${ }^{1}$ Kandidat Skripsi Fakultas Kedokteran Universitas Sam Ratulangi Manado \\ ${ }^{2}$ Bagian Fisiologi Fakultas Kedokteran Universitas Sam Ratulangi Manado \\ Email: inrynovitatentero@gmail.com
}

\begin{abstract}
Diabetes mellitus (DM) is a serious problem with the incidence rising sharply. DM can affect almost all segments of society throughout the world. The number of people with diabetes continues to grow from year to year due to poor lifestyle. People today are less likely to move and have unhealthy eating patterns. High blood sugar levels are disturb concetration to sleep, due to frequent urge to urinate during the night. Sleep disorder is a common problem that occurs in patients with DM and DM reverse can also cause sleep disturbance due to nocturia and pain complaints. The purpose of this study was to determine the relationship of the DM with the quality of sleep in out patients with DM who in the Pancaran Kasih General Hospital Manado. This research is descriptive analytic with crosssectional study. The study population was the out patients with DM in Pancaran Kasih General Hospital Manado totaling 456 people. Samples were taken using total sampling technique as much as 78 respondents who met the inclusion criteria. The data were analyzed using Pearson's correlation to determine whether there is a correlation between diabetes mellitus and sleep quality by using the application of computer programs. There is a correlation between Diabetes Mellitus with the quality of sleep in patients of Pancaran Kasih General Hospital Manado.
\end{abstract}

Keywords: diabetes mellitus, sleep quality, people with diabetes mellitus

\begin{abstract}
Abstrak: Diabetes Melitus (DM) merupakan masalah serius dengan angka kejadian yang meningkat tajam. DM dapat menyerang hampir semua golongan masyarakat di seluruh dunia. Jumlah penderita DM terus bertambah dari tahun ke tahun karena pola hidup manusia zaman sekarang yang cenderung jarang bergerak dan pola makan yang tidak sehat. Kadar gula darah yang tinggi sangat mengganggu konsentrasi untuk tidur nyenyak, dikarenakan seringnya keinginan untuk buang air kecil pada malam hari. Kadang muncul rasa haus yang berlebihan. Gangguan tidur merupakan masalah umum yang terjadi pada pasien DM dan sebaliknya DM juga dapat menimbulkan gangguan tidur akibat adanya keluhan nocturia dan nyeri. Tujuan penelitian ini adalah untuk mengetahui hubungan DM dengan kualitas tidur pada pasien DM yang melakukan pemeriksaan rawat jalan di poliklinik penyakit dalam Rumah Sakit Umum Pancaran Kasih Manado. Jenis penelitian ini bersifat deskriptif analitik dengan rancangan cross-sectional study. Populasi penelitian adalah semua pasien DM yang melakukan pemeriksaan rawat jalan di Rumah Sakit Umum Pancaran Kasih Manado yang berjumlah 456 orang. Sampel penelitian diambil menggunakan teknik total sampling sebanyak 78 responden yang memenuhi kriteria inklusi. Data-data hasil penelitian dianalisis dengan menggunakan korelasi Pearson untuk mengetahui apakah ada hubungan antara diabetes mellitus dan kualitas tidur dengan menggunakan aplikasi dari program komputer. Terdapat hubungan antara Diabetes Mellitus dengan kualitas tidur pada pasien Rumah Sakit Umum Pancaran Kasih GMIM Manado.
\end{abstract}

Kata kunci: diabetes melitus, kualitas tidur, penderita diabetes melitus 
Diabetes Melitus (DM) merupakan masalah serius dengan angka kejadian yang meningkat tajam. ${ }^{1} \mathrm{DM}$ dapat menyerang hampir semua golongan masyarakat di seluruh dunia. Jumlah penderita DM terus bertambah dari tahun ke tahun karena pola hidup manusia zaman sekarang yang cenderung jarang bergerak dan pola makan yang tidak sehat. ${ }^{2}$

Menurut WHO, pada tahun 2014, 8,5\% dari orang dewasa berusia 18 tahun dan lebih tua menderita DM. Pada tahun 2012 DM menjadi penyebab utama dari 1,5 juta kematian. $^{3}$ Pada tahun 2014, Indonesia memiliki sekitar 9,1 juta penyandang DM. Ini merupakan jumlah terbanyak kelima di dunia. ${ }^{4}$ Menurut Riset Kesehatan Dasar (Riskesdas) tahun 2013, diperkirakan 40.772 dari 1.698.831 orang yang berusia 15 tahun ke atas di Sulawesi Utara didiagnosis DM, sedangkan 20.386 lainnya belum pernah didiagnosis menderita DM oleh dokter tetapi mengalami gejala DM pada satu bulan terakhir. ${ }^{5}$

Diabetes Melitus merupakan penyakit gangguan metabolisme yang ditandai dengan meningkatnya glukosa darah. ${ }^{6} \mathrm{Hal}$ tersebut disebabkan oleh adanya gangguan pada sekresi insulin atau gangguan kerja insulin maupun keduanya. Penderita DM tidak dapat memproduksi atau tidak dapat merespon hormon insulin yang dihasilkan oleh organ pankreas, sehingga kadar gula darah meningkat. ${ }^{7}$

Kadar gula darah yang tinggi sangat mengganggu konsentrasi untuk tidur nyenyak, dikarenakan seringnya keinginan untuk buang air kecil pada malam hari. Kadang muncul rasa haus yang berlebihan. ${ }^{8}$ Gangguan tidur merupakan masalah umum yang terjadi pada pasien DM dan sebaliknya DM juga dapat menimbulkan gangguan tidur akibat adanya keluhan nocturia dan nyeri. ${ }^{9}$

Gangguan tidur adalah kelainan yang bisa menyebabkan masalah pada pola tidur, baik karena tidak bisa tertidur, sering terbangun pada malam hari, atau ketidakmampuan untuk kembali tidur setelah terbangun. ${ }^{10}$ Gangguan tidur menyebabkan berbagai gangguan seperti gangguan sistem kardiovaskular dan endokrin, serta memperberat persepsi nyeri. ${ }^{11}$ Empat gejala utama menandai sebagian besar gangguan tidur yaitu; insomnia, hipersomnia, parasomnia, dan gangguan jadwal tidur-bangun. ${ }^{12}$

Gangguan tidur membuat kualitas tidur terganggu. Kualitas tidur adalah kepuasan seseorang terhadap tidur, sehingga seseorang tersebut tidak memperlihatkan perasaan lelah, mudah terangsang dan gelisah, lesu dan apatis, kehitaman di sekitar mata, kelopak mata bengkak, konjungtiva merah, mata perih, perhatian terpecah-pecah, sakit kepala dan sering menguap atau mengantuk. ${ }^{13}$

Kualitas tidur yang buruk seperti OSA (Obstruktive Sleep Apnea) juga merupakan salah satu faktor resiko dari DM. Sebuah penelitian yang dilakukan di University of Toronto mengumpulkan koresponden sejumlah 8.600 orang dewasa yang diduga menderita OSA. Pada penelitian ini tingkat keparahan OSA setiap orang dievaluasi menggunakan pengukuran yang dikenal sebagai Apnea Hypoapnea Index (AHI), yang menunjukkan berapa kali seseorang berhenti bernapas setiap jam. Selama periode penelitian 1994 hingga 2010, sekitar $11,7 \%$ dari peserta OSA bertendensi mengidap DM tipe $2 .^{14}$

Penulis tertarik untuk mengadakan penelitian dengan judul "Hubungan diabetes mellitus dengan kualitas tidur" dikarenakan mungkin belum ada penelitian serupa di tempat ini.

\section{METODE PENELITIAN}

Penelitian ini bersifat deskriptif analitik dengan rancangan cross- sectional study.

Penelitian dilakukan di RSU. Pancaran Kasih Manado selama bulan Oktober 2016.

Populasi adalah semua pasien DM yang melakukan pemeriksaan rawat jalan di RSU. Pancaran Kasih Manado yang berjumlah 456 orang. Sampel penelitian diambil menggunakan teknik total sampling sebanyak 78 responden yang memenuhi kriteria inklusi. Kriteria inklusi yaitu: Pasien dengan diagnosa DM baru 
yang melakukan pemeriksaan rawat jalan di Poli Penyakit Dalam RSU. Pancaran Kasih Manado, Pasien DM yang menandatangani informed consent. Kriteria ekslusi yaitu: Pasien DM yang menggunakan obat tidur.

Variabel penelitian ada variabel bebas yaitu Diabetes Melitus, dan variabel terikat yaitu kualitas tidur.

Data Diabetes Melitus diperoleh melalui pemeriksaan kadar gula darah puasa, dan data kualitas tidur diperoleh menggunakan kuesioner insomnia rating scale. Data yang telah diperoleh diproses dengan aplikasi program computer menggunakan uji Pearson.

\section{HASIL PENELITIAN}

Lokasi penelitian RSU. Pancaran Kasih berlokasi di Jl. Sam Ratulangi XIII No. 6, Titiwungen, Manado - Sulawesi Utara. Rumah sakit ini mempunyai 177 tempat tidur dan terdapat 10 poliklinik salah satunya poliklinik penyakit dalam tempat dilaksanakannya penelitian.

Berdasarkan karakteristik usia, didapatkan paling banyak antara usia 45 64 tahun sebesar 57,6\%. Hasil penelitian disajikan dalam Tabel 1.

Tabel 1. Karakteristik responden menurut umur

\begin{tabular}{ccc}
\hline $\begin{array}{c}\text { Umur } \\
\text { tahun) }\end{array}$ & $\mathrm{n}$ & $\%$ \\
\hline$<45$ & 6 & 7.6 \\
$45-64$ & 45 & 57.6 \\
$>64$ & 27 & 34.6 \\
Total & 78 & 100.0 \\
\hline
\end{tabular}

Tabel 2. Karakteristik responden berdasarkan jenis kelamin

\begin{tabular}{ccc}
\hline Jenis Kelamin & $\mathrm{n}$ & $\%$ \\
\hline Pria & 44 & 65,7 \\
Wanita & 23 & 34,3 \\
Total & 67 & 100 \\
\hline
\end{tabular}

Berdasarkan karakteristik jenis kelamin penelitian ini didominasi oleh perempuan sebesar $64,1 \%$ sedangkan laki- laki hanya sebesar $35,9 \%$. Hasil penelitian disajikan dalam Tabel 2.

Berdasarkan karakteristik menurut kadar gula darah puasa didapatkan paling banyak responden memiliki kadar gula darah puasa $>110 \mathrm{mg} / \mathrm{dl}$ sebesar $74,4 \%$. Hasil penelitian disajikan dalam tabel 3

Tabel 3. Karakteristik responden berdasarkan kadar gula darah puasa

\begin{tabular}{ccc}
\hline Gula Darah Puasa & $\mathrm{n}$ & $\%$ \\
\hline$<110 \mathrm{mg} / \mathrm{dl}$ & 20 & 25.6 \\
$>110 \mathrm{mg} / \mathrm{dl}$ & 58 & 74.4 \\
Total & 78 & 100.0 \\
\hline
\end{tabular}

Berdasarkan karakteristik subjek menurut gangguan tidur didapatkan paling banyak responden memiliki gangguan tidur sebanyak 46 responden dengan persentase $59 \%$ dan yang tidak mengalami gangguan tidur sebanyak 32 responden dengan persentase $41 \%$. Hasil penelitian disajikan dalam Tabel 4.

Tabel 4. Karakteristik responden berdasarkan gangguan tidur

\begin{tabular}{ccc}
\hline Gula Darah Puasa & $\mathrm{n}$ & $\%$ \\
\hline$<110 \mathrm{mg} / \mathrm{dl}$ & 20 & 25.6 \\
$>110 \mathrm{mg} / \mathrm{dl}$ & 58 & 74.4 \\
Total & 78 & 100.0 \\
\hline
\end{tabular}

\section{Hasil Uji Normalitas}

Penelitian ini menggunakan uji Kolmogorov - Smrinov. Berdasarkan hasil uji normalitas Kolmogorov - Smrinov didapatkan nilai gula darah puasa 4.755 dan gangguan tidur 3.410. dengan nilai signifikasi $0.238>0.05$ dapat disimpulkan bahwa data yang di uji berdistribusi normal.

\section{Hasil Uji Korelasi}

Korelasi pada penelitian ini menggunakan Uji Pierson. Hipotesis nilai signifikansi $<0.05$ yaitu $\mathrm{H}_{0}$ ditolak dan $\mathrm{H}_{1}$ diterima. Dari output di atas diketahui bahwa antara gula darah puasa dan kualitas tidur dengan nilai $0.000<0.05$ dengan nilai signifikasi $0.000<0.05$ maka $\mathrm{H}_{0}$ diterima. 
Berarti terdapat korelasi yang signifikan antara diabetes mellitus dan kualitas tidur.

Tabel 5. Uji normalitas Kolmogorov Smirnov

\begin{tabular}{llrr}
\hline & & GDP & \multicolumn{1}{c}{ KT } \\
\hline $\mathrm{N}$ & & 78 & 78 \\
Normal & Mean & .9744 & .5897 \\
Parameter & Std. Deviation & .15908 & .49506 \\
$\mathrm{~s}^{\mathrm{a}}$ & & .538 & .386 \\
Most & Absolute & .436 & .293 \\
Extreme & Positive & -.538 & -.386 \\
Difference & Negative & 4.755 & 3.410 \\
$\mathrm{~s}$ & & .238 & .238 \\
Kolmogorov-Smirnov Z & & \\
Asymp. Sig. (2-tailed) & &
\end{tabular}

Tabel 5. Uji korelasi Pierson.

\begin{tabular}{llll}
\hline & & GDP & KT \\
\hline GDP & $\begin{array}{l}\text { Pearson } \\
\text { Correlation }\end{array}$ & 1 & 0.0 \\
& Sig. (2- & 0.000 & 00 \\
& $\begin{array}{l}\text { Sialed) } \\
\text { tail }\end{array}$ & & 38 \\
& N & 78 & 78 \\
KT & $\begin{array}{l}\text { Pearson } \\
\text { Correlation }\end{array}$ & 0.135 & 1 \\
& Sig. (2- & & \\
tailed) & & & \\
& $\mathrm{N}$ & 78 & 78 \\
\hline
\end{tabular}

\section{BAHASAN}

Menurut

Federasi

Diabetes

Internasional (International Diabetes

Federation/IDF), terdapat sekitar 3.3 juta orang yang didiagnosis terkena diabetes pada tahun 2014. IDF juga mencatat bahwa 90-95\% persen kasus pada orang dewasa melibatkan diabetes tipe 2. Diabetes tipe 2 cenderung berkembang lebih cepat pada mereka yang berusia antara 45 sampai 64 tahun, semakin bertambah pada usia 65 tahun ke atas. ${ }^{15}$ Hasil penelitian tersebut serupa dengan penelitiaan ini berdasarkan kategori umur. Data menunjukkan bahwa mayoritas pasien DM berada pada usia 45 64 dengan jumlah 45 responden.

Dari hasil yang di dapatkan data menunjukkan bahwa mayoritas penderita
DM berjenis berjenis kelamin perempuan yaitu 50 responden dibandingkan penderita DM yang berjenis kelamin laki-laki yaitu 28 responden. Hasil ini sama seperti penelitian yang dilakukan oleh Sartika, Wenny dan Franly dengan judul penelitian Hubungan Pola Makan Dengan Kejadian Penyakit Diabetes Melitus di Poli Interna BLU.RSUP. Prof. DR. R. D. Kandou Manado yaitu penderita DM paling banyak berjenis kelamin perempuan 23 orang (lakilaki 17 orang). Penyakit DM ini lebih sering terjadi pada perempuan, karena kebiasaan perempuan yang suka mengkonsumsi makanan-makanan yang mengandung cokelat, gula, dan jajanan jajanan siap saji, hal ini menyebabkan peningkatan kadar gula darah pada perempuan yang lebih beresiko dibanding laki-laki akibat pola makan yang tidak baik. $^{16}$

Hiperglikemi didefinisikan sebagai kadar glukosa puasa yang lebih tinggi dari $110 \mathrm{mg} / \mathrm{dll}^{17}$ Dari hasil penelitian didapatkan responden yang mengalami hiperglikemi dengan gula darah puasa lebih dari $110 \mathrm{mg}$ sebanyak 58 responden dan responden yang tidak hiperglikemi adalah 20 responden, yang mungkin pada saat dilakukan penelitian sudah dalam proses terapi.

Gangguan tidur adalah kelainan yang bisa menyebabkan masalah pada pola tidur baik karena tidak bisa tertidur, sering terbangun pada malam hari, atau ketidakmampuan untuk kembali tidur setelah terbangun. ${ }^{10}$ Pada penelitian ini responden yang memiliki gangguan tidur adalah 46 responden, sedangkan yang tidak memiliki gangguan tidur adalah 32 responden. Hasil menunjukkan bahwa responden yang memiliki gangguan tidur lebih banyak dibandingkan responden yang tidak memiliki gangguan tidur. Hal yang sama juga dilakukan Teixeira, dkk. Di San Paolo terhadap 31 pasien DM yang menunjukkan bahwa sebanyak 32,2\% pasien DM mengalami gangguan tidur. ${ }^{18}$

Berdasarkan sampel yang berjumlah 78 responden yaitu > 50, maka dilakukan uji normalitas Kolmogorov - Smrinov. Uji 
normalitas ini bertujuan untuk menentukan data yang telah dikumpulkan berdistribusi normal atau diambil dari populasi normal. Berdasarkan hasil uji normalitas Kolmogorov - Smrinov didapatkan nilai gula darah puasa 4.755 dan gangguan tidur 3.410. dengan nilai signifikasi $0.238>0.05$ dapat disimpulkan bahwa data yang di uji berdistribusi normal.

Berdasarkan hasil penelitian, hasil analisis korelasi menunjukkan terdapat hubungan antara DM dengan kualitas tidur dengan nilai signifikasi 0.000 yaitu kurang dari 0.05 yang berarti terdapat korelasi yang signifikan antara keduanya. Penelitian ini sama seperti penelitian yang dilakukan oleh Lebetubun yang berjudul Hubungan Antara Kualitas Tidur dengan Kadar Glukosa Darah Pada Penderita Diabetes Melitus Tipe 2 di RSUD. Moewardi Fakultas Kedokteran Universitas Muhammadiyah Surakarta. Perbedaan dengan penelitian ini, Lebetubun hanya meneliti DM tipe 2 saja. Lebetubun melakukan penelitian dengan menggunakan observasi analitik dengan pendekatan crosss sectional yang menunjukkan adanya hubungan yang signifikan antara kualitas tidur dengan kadar gula darah pada penderita DM. ${ }^{19}$ Hal yang sama juga pernah dilakukan oleh Arifin dengan judul penelitian Analisis Hubungan Kualitas Tidur Dengan Kadar Glukosa Darah Pasien Diabetes Melitus Tipe 2 di RSU. Nusa Tenggara Barat. Penelitian tersebut dilakukan dengan sampel sebanyak 96 responden dan didapatkan adanya hubungan kualitas tidur dengan kadar glukosa darah pasien DM dengan nilai $\mathrm{p}=0.0006^{20}$

Berdasarkan hasil pembahasan diatas, menurut peneliti DM memiliki hubungan yang signifikan dengan kualitas tidur. Tidur yang cukup merupakan salah satu kebutuhan dasar yang harus dipenuhi setiap individu, terutama pasien yang menderita DM, dimana gangguan tidur atau tidur yang kurang secara fisiologi dapat mempengaruhi peningkatan kadar glukosa darah serta berdampak terhadap kemampuan pasien dalam melakukan kegiatan sehari-hari, juga dapat mempengaruhi motivasi dan kemampuan dalam melakukan aktivitas sehari-hari.

\section{SIMPULAN}

Berdasarkan hasil penelitian yang dilakukan disimpulkan bahwa terdapat hubungan antara diabetes mellitus dengan kualitas tidur pada pasien DM yang melakukan pemeriksaan rawat jalan di RSU. Pancaran Kasih Manado.

\section{DAFTAR PUSTAKA}

1. Tandra H. Diabetes bisa sembuh: petunjuk praktis mengalahkan dan menyembuhkan diabetes. 1st ed. Jakarta: PT Gramedia Pustaka Utama, 2015. p, 1.

2. Susilo Y, Wulandari A. Cara jitu mengatasi kencing manis: Diabetes Mellitus. 1st ed. Yogyakarta: ANDI Yogyakarta, 2011. p, 5.

3. World Health Organization. Diabetes. 2016 June [cited 2016 Sep 29]. Available from: http://www.who.int/mediacentre/facts heets/fs312/en/

4. Soyjoy. Diabetes and me. 1st ed. Jakarta: PT Elex Media Komputindo, 2015. p, 2.

5. Infodatin: Pusat data dan informasi kementerian kesehatan RI. Situasi dan analisis diabetes. 2014 [cited 2016 Oct 13]. Available from: http://www.depkes.go.id/resources/do wnload/pusdatin/infodatin/infodatindiabetes.pdf

6. Budiatri F. Diabetes Melitus [makalah]. [Surakarta]: Universitas Muhammadiyah Surakarta; 2014

7. Pesanlab. Pemeriksaan lab untuk deteksi dini diabetes beserta biayanya. 2015 June 16 [cited 2016 Sep 28]. Available from: https://www.pesanlab.com/blog/peme riksaan-lab-untuk-deteksi-dinidiabetes/

8. Diabetes Melitus. Diabetes sulit tidur, bagaimana mengatasi? 2016 Mar 15 [cited 2016 Oct 13]. Available from: https://diabetics1.com/2016/03/menga pa-diabetes-sulit-tidur.html

9. Suranto E. Hubungan insomnia dengan peningkatan gula darah puasa pada pasien diabetes mellitus (DM) di 
ruang rawat inap RSUD. Dr. Moewardi [skripsi]. [Surakarta]: Stikes Kusuma Husada; 2014

10. Alodokter. Gangguan tidur. 2016 [cited 2016 Sep 29]. Available from: http://www.alodokter.com/gangguantidur

11. Imadudin MI. Pevalensi insomnia pada mahasiswa FKIK UIN angkatan 2011 pada tahun 2012 [skripsi]. [Jakarta]: Universitas Islam Negeri Syarif Hidayatullah; 2012

12. Sadock JB, Sadock VA. Tidur normal dan gangguan tidur. In: Muttaqin $\mathrm{H}$, Sihombing RNE, editors. Kaplan \& Sadock: Buku ajar psikiatri klinis. 2nd ed. USA: Buku Kedokteran EGC, 2010. p, 339.

13. Sagala VP. Budiatri F. Kualitas tidur dan faktor-faktor gangguan tidur [journal]. [Medan]: UniversitasSumatera Utara; 2013

14. Supriyatno B, Deviani R. Obstructive sleep apnea syndrome Obstructive sleep apnea syndrome pada Anak pada Anak. Sari Pediatri. 2005;7:77

15. Samadi L. Usia Rata-rata Seseorang Saat Didiagnosis Mengidap Diabetes. 2016 [cited 2016 Nov 26]. Available from: https://hellosehat.com/pusatkesehatan/diabetes-kencingmanis/berapa-usia-rata-rata-pertamakali-didiagnosis-diabetes/

16. Sumangkut S, Supit W, Onibala F. Hubungan Pola Makan Dengan
Kejadian Penyakit Diabetes Melitus Tipe-2 di Poli Interna BLU. RSUP. PROF. DR. R. D. Kandou Manado [journal]. [Manado]: Universitas Sam Ratulangi Manado; 2013. Available from:

http://web.unair.ac.id/admin/file/f_66 425_2235-4068-1-SM.pdf

17. Price SA, Wilson LM. Pankreas: Metabolisme glukosa dan diabetes mellitus. In: Hartano H, Susi N, Wulansari P,Mahanani DA, editors. Patofisiologi: Konsep klinis prosesproses penyakit. 6th ed. Jakarta: Penerbit Buku Kedokteran EGC, 2002. p, 1260.

18. Texeira CR, Zanetti ML, Pereira MCA. Nursing Diagnosis In People With Diabetes Mellitus According to Orem's Theory Of Self-Care. Original article. Acta Paul Enferm.2008; 22(4):385-91.

19. Labetubun NS. Hubungan Antara Kualitas Tidur Dengan Kadar Glukosa Darah Pada Penderita Diabetes Mellitus Tipe 2 di RSUD Dr. Moewardi. Fakultas kedokteran Universitas Muhammadiyah Surakarta. 2014

20. Arifin Z. Analisis Hubungan Kualitas Tidur Dengan Kadar Glukosa Darah Pasien Diabetes Mellitus Tipe 2 di RSU Nusa Tenggara Barat. Universitas Indonesia. Depok. 2011 